\title{
First issue of the Journal of Lithic Studies
}

\author{
Otis Crandell
}

Babeș-Bolyai University, Geology Department, Cluj-Napoca, Romania. Email: otis.crandell@ubbcluj.ro

This issue of the Journal of Lithic Studies marks two occasions. First of all it is the first issue of JLS. Secondly, it publishes part of the research presented at the recent International Symposium on Chert and Other Knappable Materials held in Iași, Romania. Both of these occasions were the result of a lot of hard work on the part of numerous people. I am glad to have been a part of them both and to have seen them come to fruition. With a little luck (and probably a lot more hard work) I think that we will see a lot more of both the journal and the symposium in the future.

\section{The journal}

Although discussion about forming a new archaeological journal dedicated specifically to lithic studies had been going on for several years, plans for this endeavour really gained momentum in discussions leading up to the symposium on knappable materials held in Iași last summer. During the symposium several colleagues (who would later become the initial members of the editorial board) discussed the logistics, benefits and difficulties of forming this journal. It was clear that it would be a very time consuming and complex undertaking, but we felt that its time had come.

As the symposium in Iași itself demonstrated, the topic of lithic studies in archaeology is a global topic and a frequent recurring one in archaeological research. From mortars to arrowheads, the topic of stone tools and raw materials comes up in research focusing on all time periods, from the Palaeolithic (predating our own species even) up to ethnographic studies of modern people. Clearly stone has played an important and recurring role in our long term history. Quite often, lithic studies are presented in a regional context only, yet there are definitely parallels on a global scale in its usage in the past and in the methods that we as researchers use to study this material. Although there is a trend today in publishing to focus on globally significant research, we may overlook the fact that regionally focused studies contribute just as much to our general understanding of the human past on a global scale. To truly promote an understanding of this field of study, it is necessary to create an international forum to present and disseminate our research. For this reason the editorial board and scientific committee were formed from specialists from around the world, each well published and known within his or her region for their contributions to the field of lithic studies.

Other than a professional interest in lithic artefacts, one of the motivations for the founding of this journal was a belief that in this modern age, with easy access to the internet,

Published by the School of History, Classics and Archaeology, University of Edinburgh ISSN: 2055-0472. URL: http://journals.ed.ac.uk/lithicstudies/

This work is licensed under a Creative Commons Attribution 2.5 UK: Scotland License. 
there is no longer justification for large publishers charging high fees to researchers for access to the latest results in scientific research. In the academic world, researchers contribute their time, energy and other resources to conduct their research and to share their findings with the world. These same researchers contribute to journals as authors, reviewers and editors all without thought of payment from publishers. Although the costs of publishing have dropped significantly with the arrival of the information age, the fees charged to researchers have in fact increased. As with traditional paper journals, our libraries are charged high fees for digital access to the articles which their own staff and students have produced. In recent years it has also become common for universities to pay journals to make articles by their researchers available to the public free of charge. Sometimes researchers themselves pay unreasonable fees just to make their own research free to the public. The Journal of Lithic Studies was created as an alternative to this model of journal publishing. In the spirit of open scholarship, JLS is freely available to the general public. There are no fees to download articles, nor are there any fees to submit, review or publish articles. All articles in JLS are licensed under a Creative Commons Attribution 2.5 UK: Scotland License.

One of the innovations of JLS over many traditional print journals is that the primary version of the journal is in fact the digital version. As an electronic publication, authors can take advantage of the wide variety of media available in this format in addition to those available in the traditional paper format. This means that authors can incorporate audio, video, 3D images, and supplementary files such as GIS shape files, spreadsheet data, and CAD graphics into their articles. Indeed, some of the article types which can take particular advantage of diversity of this media formats are interviews and demonstrations of experimental processes or investigative procedures.

We believe that it is important for researchers to publish their work and start disseminating it in a timely manner. Although the journal is published twice a year, individual articles are available online within a few days of being approved by reviewers and the editorial board. We also aim to review article submissions within a month and let the authors know quickly regarding the status of their submissions. This not only reduces the wait time for authors but also allows authors to make revisions sooner, which ultimately allows them to disseminate their findings much faster.

A lot of people have contributed to make this first issue a reality. The Journal of Lithic Studies is published by the School of History, Classics and Archaeology, of the University of Edinburgh and is hosted by the University of Edinburgh Journal Hosting Service. I would like to extend my thanks to the staff of the Journal Hosting Service (in particular Angela Laurins) for not only hosting the journal but also for taking care of a lot of the technical and administrative aspects of setting up the journal. Thanks to Clive Bonsall, we were able to find a host for the journal at the University of Edinburgh. The members of the Editorial Board played an important role in establishing the nature, objectives and policies of the journal. Although these will likely evolve over time, they were necessary to start the journal off. Thanks are also due to the members of the scientific committee and the various reviewers who took the time to evaluate article submissions for the first issue and in many cases provide the authors with advice (often quite detailed) on how to improve the articles. And of course this issue would not have been possible without one very important group of people - the authors. To everyone who submitted an article for this first issue, I would like to thank you for your support for the journal and in our efforts to promote a global dissemination on the topic of lithic studies though a truly researcher-oriented publication model. 


\section{The symposium}

Last summer, specialists in lithic studies from around the world met in north-eastern Romania for an archaeological symposium on various subjects related to knapped artefacts and knappable materials. Titled "Stories Written in Stone" the International Symposium on Chert and Other Knappable Materials took place from 20 to 24 August 2013 in the city of Iaşi. This event was organised by myself and Vasile Cotiugă and hosted by the Arheoinvest archaeometry centre of the Alexandru Ion Cuza University. This event was also run in partnership with the Center for Obsidian and Lithic Studies at Meiji University, the International Association for Obsidian Studies, and the Society for Archaeological Sciences.

Fifty three presenters and several additional participants attended the symposium in person, along with six volunteer assistants, and faculty and students from the History Department. We had the pleasure to listen to 46 talks and look through 35 posters. One of the very interesting innovations of this symposium, something which set it aside from most other archaeology symposia was the possibility for presenters to participate via the internet. Using specialised conferencing software, 22 people presented their research without having to leave the comfort of their home or office. Two people even came online to give their presentations and answer questions while they were doing field work. In addition, they could watch the symposium and take part in the question and answer periods as well. In my mind, this was a major step forward. One of large difficulties in holding a truly international symposium is attracting participants representative of the academic community beyond the regional level. For various reasons, many people, and in particular young researchers, are not able to attend events in other countries. The online presentations allowed us to interact with colleagues that we would have otherwise not heard from. I hope that we see more of this option in future events in the archaeological community.

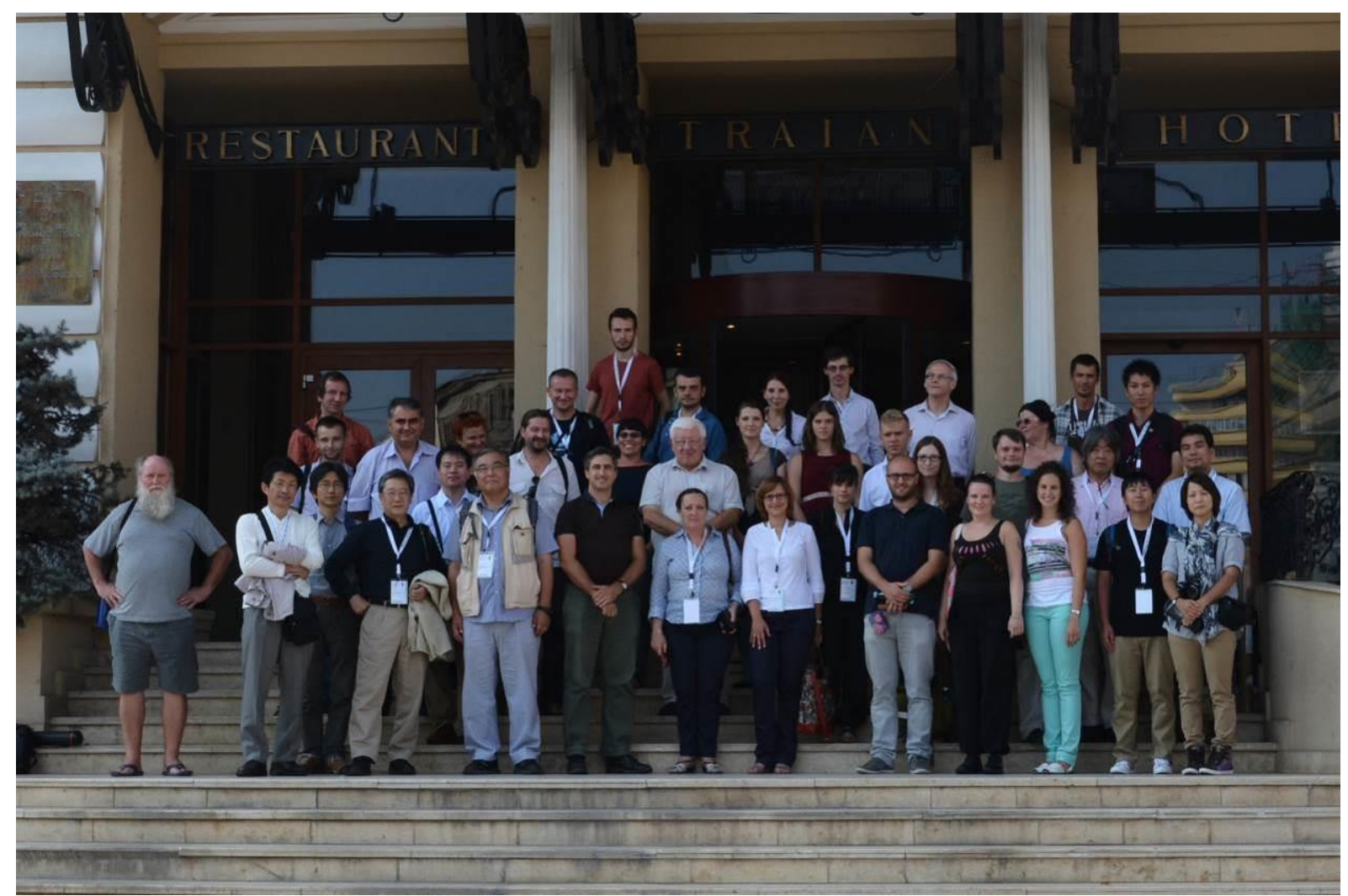

Figure 1. "Stories Written in Stone" International Symposium on Chert and other Knappable Materials. Symposium. (Photo by Bogdana Milic.) 
The other aspect of this symposium that I liked was the diversity of presentations and presenters. There were people from nineteen different countries, often presenting on research from even more countries. Researchers from countries in Europe, Asia, North and South America, and Africa presented their work on all time periods, ranging from the Palaeolithic to the $19^{\text {th }}$ century. As far as session topics, the symposium was divided into two general themes - 'The chaîne opératoire of knapped stone artefacts', and 'Auxiliary sciences related to microcrystaline quartz'. Each theme was further divided into the following specific sessions.

Theme 1: Chaîne opératoire

- Session 1: raw material exploitation strategies: mining and surface collecting;

- Session 2: ancient lithic trade and economics;

- Session 3: stone tool production and processing techniques;

- Session 4: use-wear analyses: signs of usage on stone tools.

Theme 2: Auxiliary sciences

- Session 5: characterising lithic sources;

- Session 6: lithotheques collections of comparative raw materials;

- Session 7: gemology - silica as a gemstone today and in the past.

Additionally, one special topic session on obsidian was organised by researchers at the Center for Obsidian and Lithic Studies at Meiji University. The abstracts for the presentations have been published by the "Alexandru Ioan Cuza" University of Iași Press, edited by Otis Crandell and Vasile Cotiugă and reviewed by the members of the symposium's scientific committee. Further details about the symposium can be found on the symposium web site http://arheoinvestsymposium.uaic.ro/stone/ .

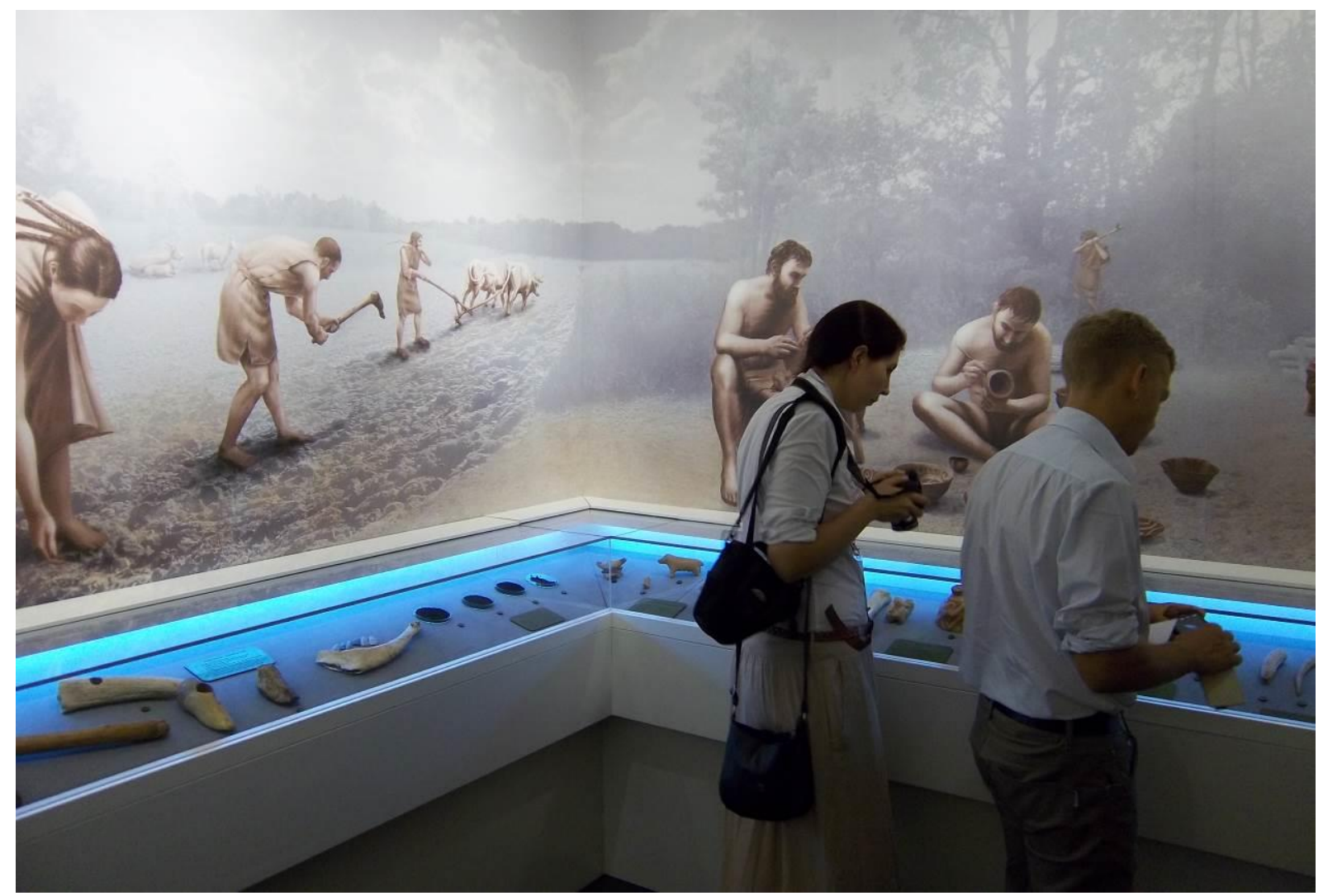

Figure 2. A visit to the Cucuteni Civilisation Museum. (Photo by Otis Crandell.) 
In addition to the scientific programme, this symposium had a diverse and entertaining social events programme filled with various museum visits (including a special exhibit about the history of stone tool usage in the region), dinners, and traditional music and dance performances at the farewell party. The highlight of the social events programme was the excursion to the Prut River in Botoșani County. The first stop on the excursion was at the modern flint mine outside Miorcani. In addition to seeing one of the few modern flint mines still around, it was also an opportunity for regional researchers to collect some sample of a regional high quality material used throughout prehistory. It is always nice to collect some rock souvenirs. After the mines, we visited the Palaeolithic sites of Mitoc and Ripiceni (which is now mainly underwater).

Thanks are owed to the members of the scientific and planning committees for all of the hard work they did leading up to and during the symposium. Special thanks are due to Vasile Cotiugă for the crucial role he played in managing the logistics of the symposium. If not for his work, there would have been no symposium at all. The student from AIC University who volunteered during the symposium deserve recognition for the great job they did in making sure that things ran smoothly. Lastly, I would like to thank all of the presenters for taking part in the symposium and telling us about your research.

The next international symposium on knappable materials will be hosted by the University of Barcelona in September of 2015. The website for the next symposium will be at http://cherts-symp2015.net/ . From what I've heard, the organisers in Spain have an interesting and informative schedule planned.

I hope to see all of you again soon - perhaps in Barcelona, perhaps at another meeting. Until then, I look forward to reading about your research and I wish you all continued success.

Otis Crandell

Editor-in-Chief Journal of Lithic Studies

Symposium President (2013) International Symposium on Chert and Other Knappable Materials 


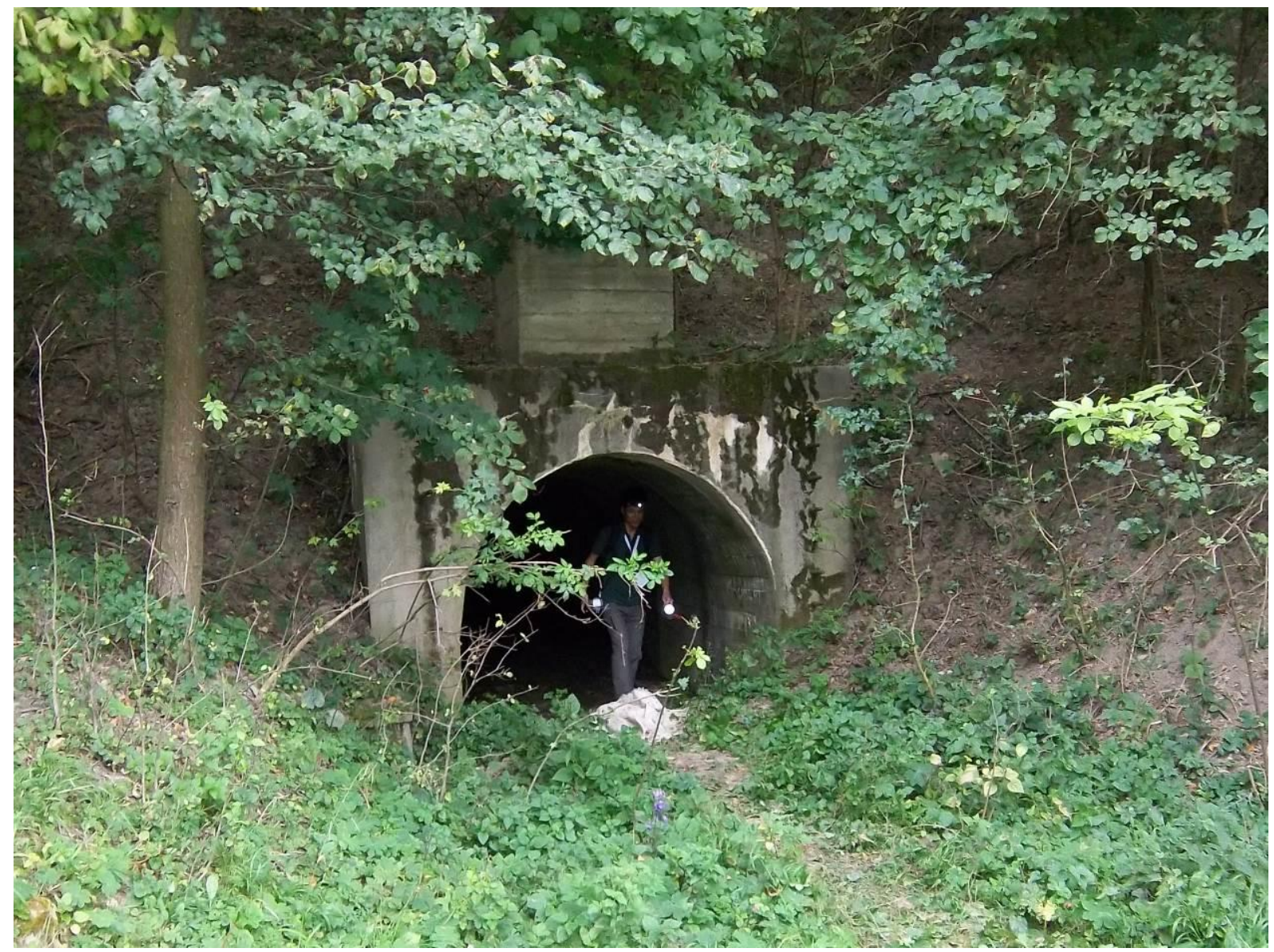

Figure 3. The Miorcani flint mines. (Photo by Otis Crandell.)

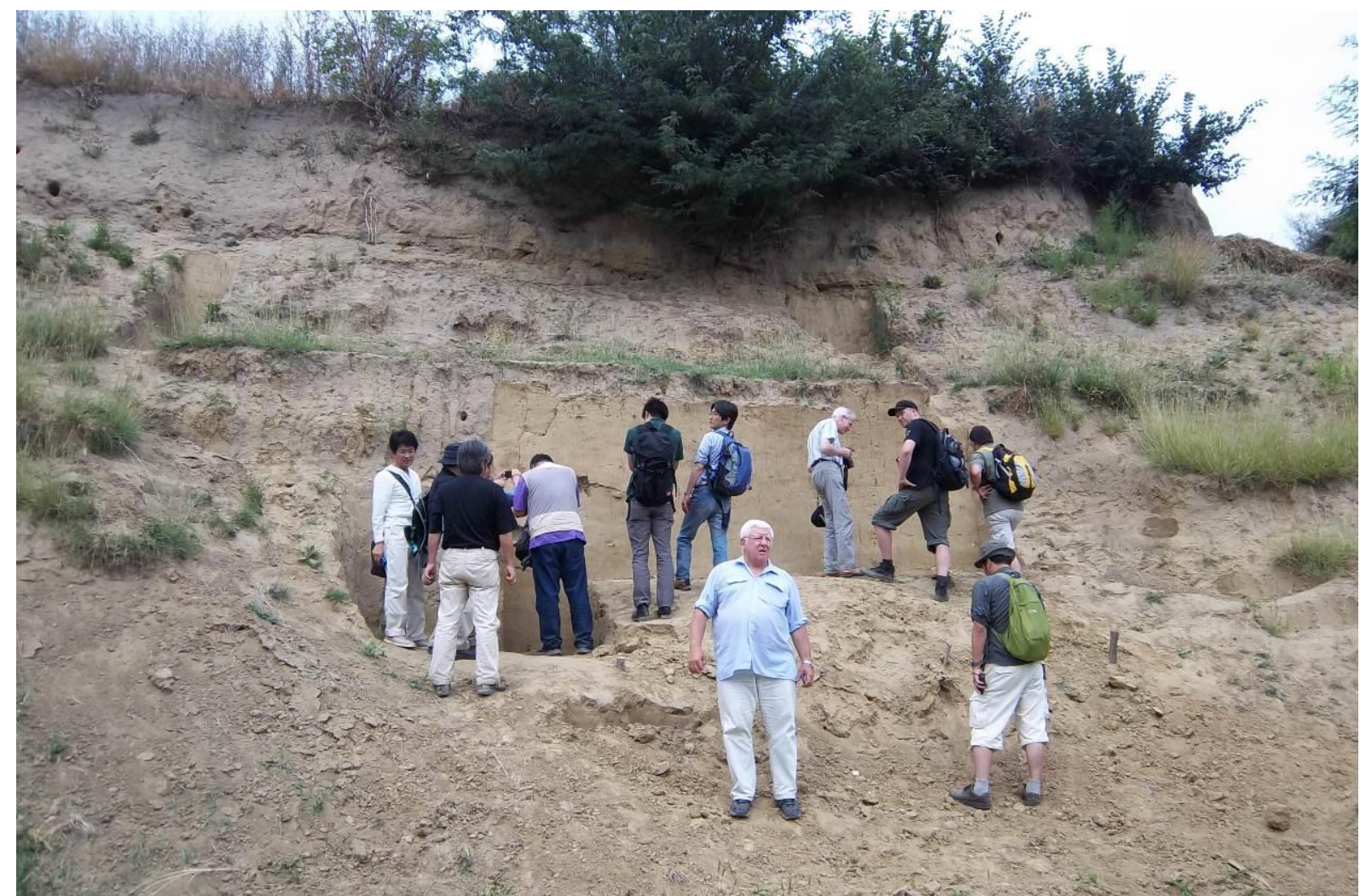

Figure 4. A visit to the Palaeolithic site of Mitoc. (Photo by Otis Crandell.) 